\title{
The in vitro antitumor activity of Siegesbeckia glabrescens against ovarian cancer through suppression of receptor tyrosine kinase expression and the signaling pathways
}

\author{
YOUNG-RAK $\mathrm{CHO}^{1 *}$, SHIN WOOK CHOI ${ }^{2 *}$ and DONG-WAN SEO ${ }^{1}$ \\ ${ }^{1}$ College of Pharmacy, Dankook University, Cheonan 330-714; \\ ${ }^{2}$ Radiant Research Institute, Radiant Inc., Chuncheon 200-883, Republic of Korea
}

Received February 14, 2013; Accepted April 29, 2013

DOI: $10.3892 /$ or.2013.2468

\begin{abstract}
Siegesbeckia glabrescens (SG) Makino(Compositae) has been used as a traditional medicine for the treatment of a variety of diseases such as allergy, inflammation, acute hepatitis and hypertension. The primary aim of this study was to determine whether the ethanol extract of SG has antitumor activity against ovarian cancer and to identify molecular mechanisms and targets involved in the regulation of cell growth and progression. We demonstrate that SG treatment inhibits proliferation, adhesion, migration and invasion of SKOV-3 human ovarian cancer cells. The anti-proliferative effect of SG on SKOV-3 cells is accompanied by reduced expression of cyclin $\mathrm{E}$ and enhanced expression of the cyclin-dependent kinase inhibitor $\mathrm{p} 27^{\mathrm{Kip} 1}$, leading to inhibition of $\mathrm{pRb}$ phosphorylation. We also show that these antitumor activities are found to be mediated through suppression of FAK, ERK, Akt and p70 56 dependent signaling pathways and downregulation of receptor tyrosine kinases such as EGFR, VEGFR-2 and FGFR-1 as well as the cell adhesion molecule N-cadherin. Taken together, our findings suggest further development and evaluation of SG for the treatment of ovarian cancer.
\end{abstract}

\section{Introduction}

Epithelial ovarian cancer is the leading cause of cancer death among the gynecological malignancies and its incidence rate is highest in Western industrialized countries. A lack of early symptoms or screening methods of ovarian cancer often

Correspondence to: Professor Dong-Wan Seo, Laboratory of Biochemistry, Department of Pharmacy, College of Pharmacy, Dankook University, 119 Dandae-ro, Cheonan 330-714, Republic of Korea

E-mail: dwseomb@dankook.ac.kr

*Contributed equally

Key words: Siegesbeckia glabrescens, ovarian cancer, proliferation, migration, invasion, receptor tyrosine kinases leads to late diagnosis in advanced stage and subsequent high mortality rate (1). Moreover, no highly effective therapeutics and strategies against metastatic and recurrent ovarian cancers have been established.

Receptor tyrosine kinases (RTKs) play pivotal roles in cellular process including proliferation, migration and survival. Mutations in RTKs and dysregulated activation of their intracellular signaling pathways have been reported to be closely involved in a variety of diseases such as cancers, angiogenesis, and inflammation (2). RTKs such as epidermal growth factor receptor (EGFR), vascular endothelial growth factor receptor (VEGFR) and fibroblast growth factor receptor (FGFR) are highly expressed or activated in ovarian cancer (3-8). Selective inhibition of RTK activation or downstream signaling pathways appears to be a potent strategy with little or no side effects, compared to conventional therapy. Epithelial-to-mesenchymal transition (EMT), commonly occurs in epithelial cancers, it is a cellular process which involves changes in cellular morphology, the loss and remodeling of cell-cell and cell-matrix adhesions, and subsequent acquisition of cell migration and invasion (9). During EMT, expression of the epithelial markers such as epithelial cadherin (E-cadherin) and claudins is reduced, whereas that of mesenchymal markers including neural-cadherin (N-cadherin), integrin $\alpha 5 \beta 1$, and matrix metalloproteinases (MMPs) is increased (10-12). EMT-associated cancer cell invasion and metastasis are mediated by the tissue remodeling due to changes in expression levels of cell adhesion molecules and/ or elevated levels of secreted proteolytic enzymes including MMPs (13). Therefore, unraveling the molecular mechanisms and targets of ovarian cancer progression within the context of extracellular matrix (ECM) and the function of the tumor microenvironment may help to improve current concepts and therapies for the treatment of ovarian cancer.

Siegesbeckia glabrescens (SG) Makino (Compositae) has been used as a traditional medicine for the treatment of allergic diseases, paralysis, acute hepatitis, and hypertension. Many investigations have demonstrated that the extracts and biologically active components of SG have anti-allergic and anti-inflammatory activities (14-17). In addition, the water extract of SG has been reported to have antitumor activity against breast cancer cells by inducing apoptosis (18), 
however, the effects and molecular mechanisms of SG on other cancer cells remain unexplored. In the present study, we evaluated the regulatory effects and signaling pathways of SG on proliferation, adhesion, migration and invasion in ovarian cancer cells.

\section{Materials and methods}

Cell culture conditions. Human ovarian carcinoma cells (SKOV-3) from American Type Culture Collection (Manassas, VA, USA) were grown in $10 \%$ fetal bovine serum-Dulbecco's modified Eagle's medium(FBS-DMEM) (HyClone Laboratories, Logan, UT, USA).

Reagents. The following antibodies were purchased from commercial sources: anti-integrin $\beta 1$, anti-N-cadherin, anti-phospho-FAK (Y397), anti-FAK, (BD Biosciences, Bedford, MA, USA); anti-phospho-Src (Y416), anti-Src, anti-phospho-ERK (T202/Y204), anti-phospho-Akt (S473), anti-phospho-p70 ${ }^{\mathrm{S} 6 \mathrm{~K}}$ (T421/S424), anti-phospho-pRb (S780), anti-phospho-pRb (S807/S811), anti-pRb (Cell Signaling, Beverly, MA, USA); anti-EGFR, anti-VEGFR-2, anti-FGFR-1, anti-ILK, anti-ERK, anti-Akt, anti-p70 ${ }^{\mathrm{S} 6 \mathrm{~K}}$, anti-MMP-2, anti-Cdk4, anti-Cdk2, anti-cyclin D, anti-cyclin E, anti-actin antibodies, and mouse and rabbit IgG-horseradish peroxidase conjugates (Santa Cruz Biotechnology, Santa Cruz, CA, USA).

Preparation of SG extract. The ethanol extract was prepared by mixing $100 \mathrm{~g} \mathrm{SG}$ with 1 liter of ethanol and stirring for $90 \mathrm{~min}$. The extract was then filtered through a filter paper (Advantec no. 5C, Toyo Roshi Kaisha, Tokyo, Japan), and the filtrate was concentrated using a rotary evaporator (Heidolph Instruments $\mathrm{GmbH} \& \mathrm{Co}$., Schwabach, Germany) at $46^{\circ} \mathrm{C}$ under vacuum. The yield of the dried extract was approximately $6.5 \mathrm{~g} / 1$.

Cell growth assay. SKOV-3 cells, plated on 6-well plates ( $2 \times 10^{4}$ cells/well, BD Biosciences), were serum-starved for $24 \mathrm{~h}$ to synchronize cells in $\mathrm{G}_{1} / \mathrm{G}_{0}$ phase of the cell cycle, and further incubated with $10 \%$ FBS-DMEM for $24 \mathrm{~h}$ in the presence of SG at different concentrations $(0.1-10 \mu \mathrm{g} / \mathrm{ml})$. The cells were then washed in ice-cold phosphate buffered saline (PBS, pH 7.4), detached with trypsin, and counted using trypan blue exclusion method $(19,20)$. The results from triplicate determinations (mean \pm standard deviation) are presented as the fold-increase of untreated controls.

Western blot analysis. Subconfluent cells in 100-mm dishes (BD Biosciences) were serum-starved for $24 \mathrm{~h}$ in DMEM and replaced with fresh media, followed by treatments for different time points, as indicated, at $37^{\circ} \mathrm{C}$. Cells were rinsed twice with ice-cold PBS and lysed by incubation in $50 \mathrm{mM}$ Tris- $\mathrm{HCl}$ (pH 7.4), $150 \mathrm{mM} \mathrm{NaCl}, 10 \%$ glycerol, $1 \%$ Triton $\mathrm{X}-100$, $1 \mathrm{mM}$ EDTA, $100 \mu \mathrm{g} / \mathrm{ml}$ 4-(2-aminoethyl)benzenesulfonyl fluoride, $10 \mu \mathrm{g} / \mathrm{ml}$ aprotinin, $1 \mu \mathrm{g} / \mathrm{ml}$ pepstatin $\mathrm{A}, 0.5 \mu \mathrm{g} / \mathrm{ml}$ leupeptin, $80 \mathrm{mM} \beta$-glycerophosphate, $25 \mathrm{mM}$ sodium fluoride and $1 \mathrm{mM}$ sodium orthovanadate for $30 \mathrm{~min}$ at $4^{\circ} \mathrm{C}$. Cell lysates were clarified at $13,000 \mathrm{x} \mathrm{g}$ for $20 \mathrm{~min}$ at $4^{\circ} \mathrm{C}$, and the supernatants were subjected to western blot analysis as previously described (21).
Adhesion assay. Subconfluent cells were detached with trypsin and allowed to recover in $10 \%$ FBS-DMEM for $1 \mathrm{~h}$ at $37^{\circ} \mathrm{C}$ with gentle rocking. After recovery, the cells were collected by low-speed centrifugation and resuspended in serum-free DMEM. The cell suspension was pretreated with or without SG for $30 \mathrm{~min}$, and followed by serum treatment. The cells were plated on 96 -well plates $\left(1.5 \times 10^{4}\right.$ cells/well $)$, and further incubated for $2 \mathrm{~h}$ at $37^{\circ} \mathrm{C}$. Following incubation unattached cells were removed by washing the wells three times with PBS. Attached cells were fixed with methanol, and then stained with $0.04 \%$ Giemsa staining solution (Sigma-Aldrich Co., St. Louis, MO, USA). The cells were photographed and counted. The results (mean \pm standard deviation) are presented as the numbers of adherent cells (22).

Migration assay. Cell migration was quantified in the in vitro wound-healing assay as previously described $(23,24)$. After cells were plated on 48-well plates, and grown to confluence, a single wound was created in the center of the cell monolayer by the gentle removal of the attached cells with a sterile plastic pipette tip. Following incubation with serum-free DMEM for $2 \mathrm{~h}$, cells were pretreated with or without SG for $30 \mathrm{~min}$, followed by serum stimulation for $14 \mathrm{~h}$. Cells were fixed with methanol, and then stained with $0.04 \%$ Giemsa solution. The migration of the cells into the wound was observed with still images taken at the indicated time points.

Invasion assay. The upper side of the transwell insert (Costar, $6.5 \mathrm{~mm}$ diameter insert, $8 \mu \mathrm{m}$ pore size) (Corning Inc., Corning, NY, USA) was coated with $50 \mu \mathrm{l}$ of $1 \mathrm{mg} / \mathrm{ml}$ Matrigel (BD Biosciences) diluted in serum-free DMEM at $37^{\circ} \mathrm{C}$. Aliquots $(100 \mu \mathrm{l})$ of cells $\left(8 \times 10^{5}\right.$ cells $\left./ \mathrm{ml}\right)$ resuspended in serum-free DMEM were added to the upper compartment of the Matrigelcoated transwell and $600 \mu \mathrm{l}$ of serum-free DMEM was added to the lower compartment. After serum starvation for $2 \mathrm{~h}$, cells were pretreated with or without SG for $30 \mathrm{~min}$, followed by serum stimulation for $15 \mathrm{~h}$. The inserts were fixed with methanol and using a cotton-tipped swab the non-invasive cells were removed from the top of the membrane. After staining with $0.04 \%$ Giemsa solution, the number of invasive cells was determined from six different fields using x200 objective magnification (25).

Zymogram analysis. Activities of matrix metalloproteinases (MMPs) were measured by zymography $(21,26)$. Aliquots of conditioned medium were diluted in sample buffer, applied to $10 \%$ polyacrylamide gels containing $1 \mathrm{mg} / \mathrm{ml}$ gelatin (SigmaAldrich Co.) as a substrate. After electrophoresis, the gels were incubated in $2.5 \%$ Triton X-100 for $1 \mathrm{~h}$ to remove SDS and allow re-naturalization of MMPs, and further incubated in developing buffer containing $50 \mathrm{mM}$ Tris- $\mathrm{HCl}(\mathrm{pH} 7.5)$, $10 \mathrm{mM} \mathrm{CaCl}_{2}$, and $150 \mathrm{mM} \mathrm{NaCl}$ for $15 \mathrm{~h}$ at $37^{\circ} \mathrm{C}$. The gels were stained with $0.5 \%$ Coomassie brilliant blue R-250 in $30 \%$ methanol-10\% acetic acid for $2 \mathrm{~h}$ and followed by destaining with $30 \%$ methanol-10\% acetic acid. Gelatinolytic activities were detected as unstained bands against the background of the Coomassie blue-stained gelatin.

Statistical analysis. Statistical analysis was performed using Student's t-test, and was based on at least three different 

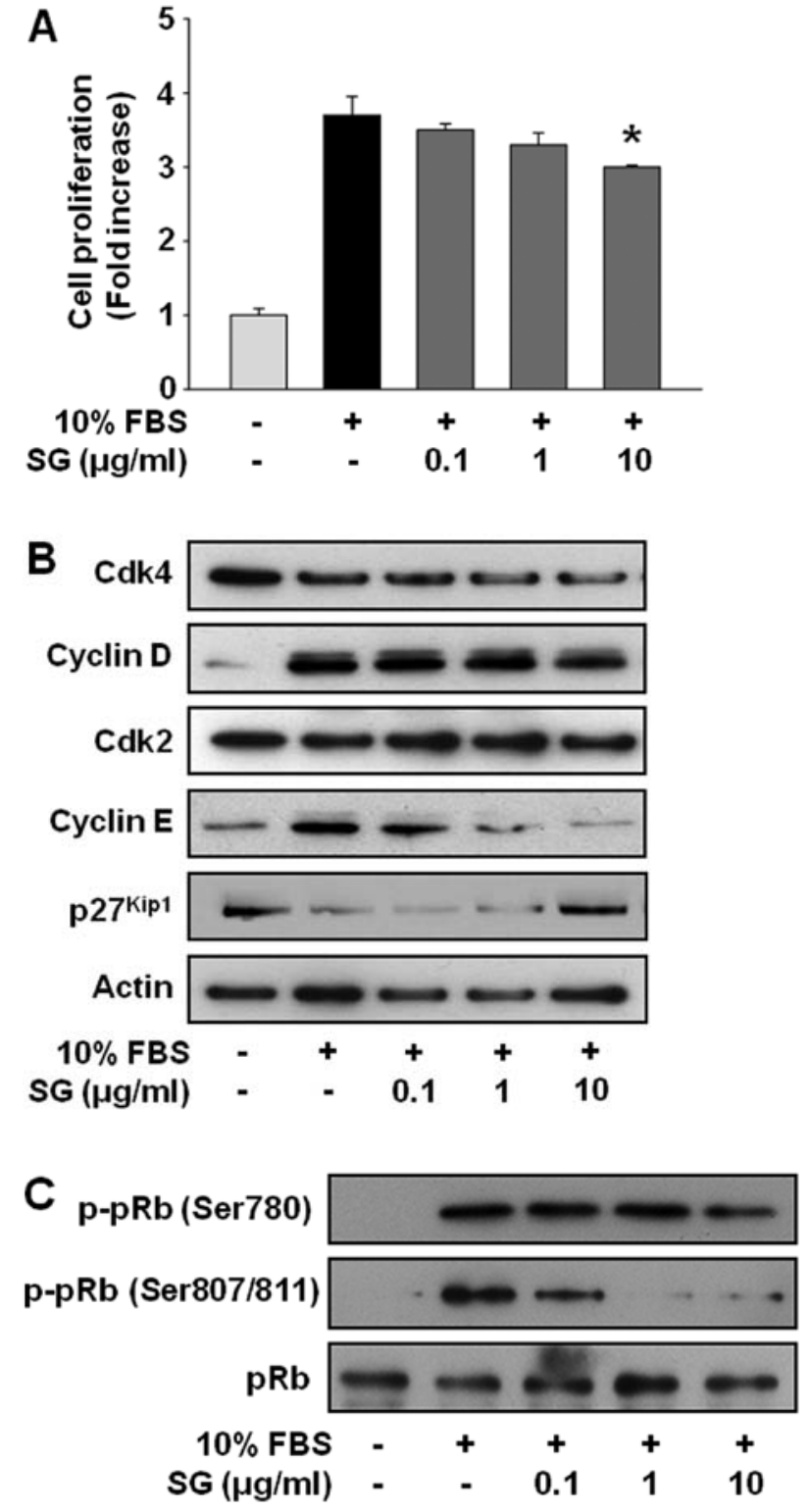

Figure 1. SG treatment suppresses proliferation by downregulation of cyclin E and upregulation of p27 ${ }^{\mathrm{Kip} 1}$ in SKOV-3 cells. (A) Quiescent cells were pretreated with or without SG at different concentrations $(0.1-10 \mu \mathrm{g} / \mathrm{ml})$ for $30 \mathrm{~min}$, followed by $10 \%$ serum stimulation for $24 \mathrm{~h}$. Cell proliferation results from three independent experiments (mean $\pm \mathrm{SD}$ ) are presented as the fold-increase of untreated controls. Statistical significance is indicated $\left({ }^{*} \mathrm{p}<0.05\right.$, compared with $10 \%$ serum-treated cells). (B and C) Cell lysates were western blotted with anti-Cdk4, anti-cyclin D, anti-Cdk2, anti-cyclin E, anti-p27 ${ }^{\text {Kip1 }}$, anti-actin, anti-phospho-pRb (S780), anti-phospho-pRb (S807/S811), or anti-pRb antibodies. Results shown are representative of at least three independent experiments.

experiments. The results were considered to be statistically significant when $\mathrm{p}<0.05$.

\section{Results}

SG suppresses cell proliferation through modulating the expression of cell cycle-related proteins. We first examined the effect of SG on cell proliferation in SKOV-3 cells. SG treatment marginally, but significantly, suppressed cell proliferation in a dose-dependent manner (Fig. 1A). Based on these findings, we next analyzed the changes of cell cycle-related proteins. It has

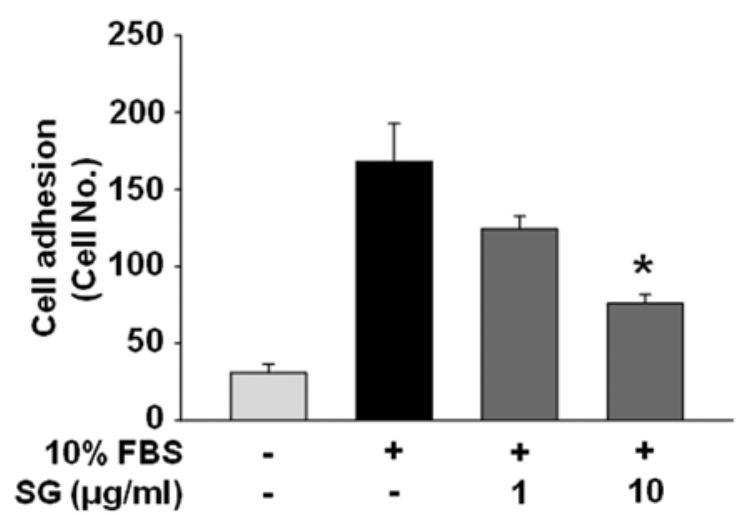

Figure 2. SG treatment inhibits cell adhesion. The number of attached cells was determined by counting six random fields of cells (x100 magnification) as described in Materials and methods. Cell adhesion results from six independent experiments (mean $\pm \mathrm{SD}$ ) are presented as the number of adherent cells. Statistical significance is indicated $\left(^{*} \mathrm{p}<0.05\right.$, compared with $10 \%$ serum-treated cells).

been reported that cell cycle progression requires activation of cyclin-dependent kinases (Cdks) through formation with cyclins and subsequent phosphorylation of retinoblastoma protein $(\mathrm{pRb})$, resulting in transition from $\mathrm{G} 1$ to $\mathrm{S}$ phase of the cell cycle. The kinase activity of these complexes is regulated by the Cip/Kip family of Cdk inhibitors such as $\mathrm{p} 27^{\mathrm{Kip} 1}$ and p2 $1^{\mathrm{WAF} 1 / \mathrm{Cip} 1}$ as well as INK-4 family that specifically inhibit Cdk4/6-cyclin D complexes (27). SG treatment dramatically downregulated the expression of cyclin $\mathrm{E}$ and upregulated the p2 $7^{\text {Kipl }}$ levels to levels observed in untreated controls (Fig. 1B). However, SG treatment did not significantly affect the levels of Cdk4, Cdk2, and cyclin D but decreased those of Cdk4 and cyclin D reproducibly (Fig. 1B). In addition, we analyzed the phosphorylation of $\mathrm{pRb}$ on residues Ser 780 and Ser 807/811, sites specific for Cdk4 and Cdk2 phosphorylation, respectively. As shown in Fig. 1C, SG treatment dose-dependently suppressed $\mathrm{pRb}$ phosphorylation at both sites, in good agreement with the expression levels of Cdks and cyclins (Fig. 1B). Collectively, these findings demonstrate that SG regulates the expression of cell cycle-related proteins and subsequent phosphorylation of $\mathrm{pRb}$, resulting in inhibition of cell cycle progression and proliferation.

$S G$ inhibits ovarian cancer cell adhesion, motility and invasion. Cell adhesion and migration associated with EMT and tumor microenvironment are controlled by coordinated processes through the interactions with ECMs as well as intercellular components (9-12). We next examined the effects of SG on adhesion, migration and invasion of SKOV-3 cells in response to mitogenic stimulation. SG treatment markedly inhibited cell adhesion, migration, invasion in a dose-dependent manner (Figs. 2 and 3A and B). Expression and activation of MMPs have been reported to promote cell migration and invasion by selective proteolytic degradation of ECM components (13). Based on SG-mediated inhibition of cell migration and invasion, we analyzed the levels of MMPs in SKOV-3 cells . SG treatment showed little or no change of expression and activity of MMP-2 and MMP-9 (Fig. 3C and D), suggesting the existence of alternative mechanism to inhibit cell migration 

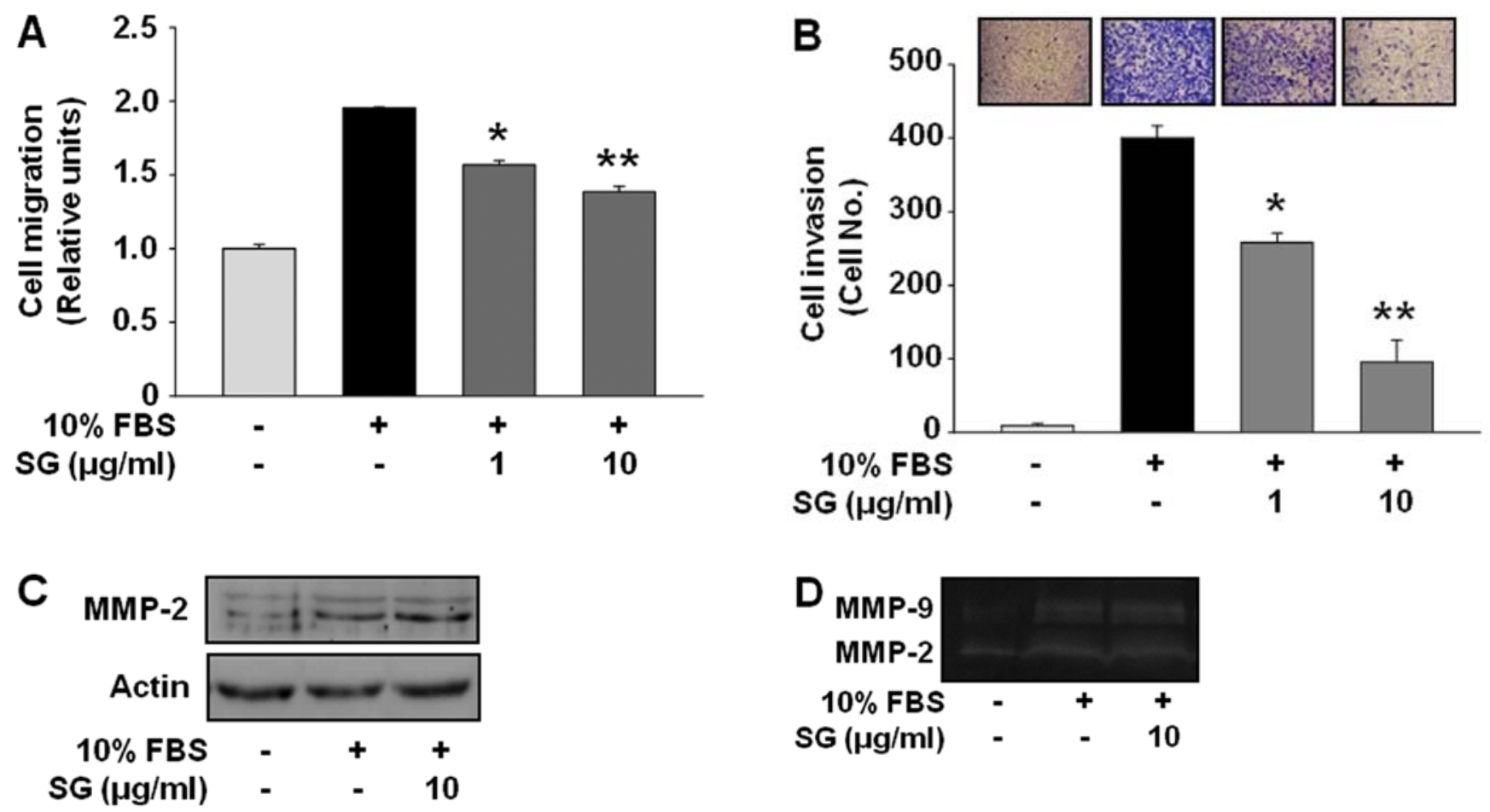

Figure 3. SG treatment blocks cell migration and invasion. (A) Cell migration was quantified by measuring the migration distance of cells from wound edge as described in Materials and methods. Results from six independent experiments (mean \pm SD) are represented as the fold-increase of untreated controls. (B) The number of invasive cells was determined by counting six different fields of cells (x200 magnification). Results from six independent experiments (mean \pm SD) are presented as the number of invasive cells. Statistical significance is indicated ( $\mathrm{p}<0.05,{ }^{* * *} \mathrm{p}<0.01$, compared with $10 \%$ serum-treated cells). (C) Quiescent cells were pretreated with SG (10 $\mu \mathrm{g} / \mathrm{ml})$ for $30 \mathrm{~min}$, followed by $10 \%$ serum stimulation for $24 \mathrm{~h}$. Cell lysates were western blotted with anti-MMP-2 or antiactin antibodies. (D) Gelatin zymogram analysis was carried out by using conditioned media from cell culture treated as in (C). Zymogram gel loading was normalized to total protein concentration. Results are representative of at least three independent experiments.

and invasion by SG treatment, and this mechanism appears to be independent of regulation of MMP activity.

In vitro antitumor effects of SG on ovarian cancer are mediated through inhibition of mitogenic signaling pathways, and downregulation of receptor tyrosine kinases and $\mathrm{N}$-cadherin. To further investigate the molecular mechanisms by which $\mathrm{SG}$ regulates cell fates, we examined the changes in activation of intracellular signaling components including focal adhesion kinase (FAK), Src, extracellular signal-regulated kinase (ERK), phosphatidylinositol 3-kinase (PI3-K)/Akt, and mammalian target of rapamycin (mTOR)/p70 $0^{\mathrm{S} 6 \mathrm{~K}}$ and expression of RTKs including EGFR, VEGFR-2, and FGFR-1 which play the pivotal roles in cell proliferation, migration, and invasion $(2,28)$. As expected, mitogenic stimulation for $15 \mathrm{~min}$ markedly increased the phosphorylation/activation of FAK, ERK, Akt, and $\mathrm{p} 70^{\mathrm{S} 6 \mathrm{~K}}$, but not that of Src, when compared with unstimulated controls (Fig. 4A). SG treatment significantly inhibited the phosphorylation of FAK, ERK, Akt and p70 $56 \mathrm{~K}$ in a dose-dependent manner. This suppression of downstream signaling pathways of integrins and RTKs appears to mediate anti-proliferative, anti-adhesive, anti-migratory and antiinvasive properties of SG in ovarian cancer cells.

We next analyzed the changes in the expression of RTKs and integrin $\beta 1$, which are overexpressed and correlate with ovarian cancer progression and metastatic potential (4,6-8,29-31). As shown in Fig. 4B, SG treatment markedly inhibited mitogeninduced expression of EGFR, VEGFR-2 and FGFR-1, but not that of integrin $\beta 1$, to levels observed in unstimulated controls. In addition, SG treatment suppressed the expression of integrinlinked kinase (ILK), which can interact with the cytoplasmic domain of integrin $\beta$ subunit and is activated by both integrin activation and growth factors (32). Finally, pretreatment of cells with PD98059, an inhibitor of ERK pathway, LY294002, an inhibitor of PI3-K/Akt pathway, or rapamycin, an inhibitor of $\mathrm{mTOR} / \mathrm{p} 70^{\mathrm{S} 6 \mathrm{~K}}$ pathway, mimicked the suppressive effects of SG on RTK expression (Fig. 4C), cell proliferation, adhesion, and migration (data not shown), indicating that the ethanol extract of SG contains the pharmacologically effective components, similar to these inhibitors, and may share the roles and mechanisms of action in regulating cell fates.

Loss of E-cadherin from the cell surface, commonly occurs in cancer progression, resulting in disruption of cell-cell contacts, cell detachment, cell shape change, cell migration and invasion. On the other hand, elevation of $\mathrm{N}$-cadherin, one of the mesenchymal markers, induces EMT and cancer progression $(9,13)$. Alteration in cadherin function can be assessed by the levels of cadherin detectable in the Triton X-100 insoluble cell extracts. As shown in Fig. 5, SG treatment completely inhibited mitogen-stimulated distribution of $\mathrm{N}$-cadherin in detergent-insoluble fraction to levels observed in unstimulated controls, however, did not alter the expression of N-cadherin in detergent-soluble fraction. In contrast, the expression of E-cadherin in SKOV-3 cells was not clearly detectable (data not shown). Taken together, these findings demonstrate that suppression of cell proliferation, adhesion, migration and 

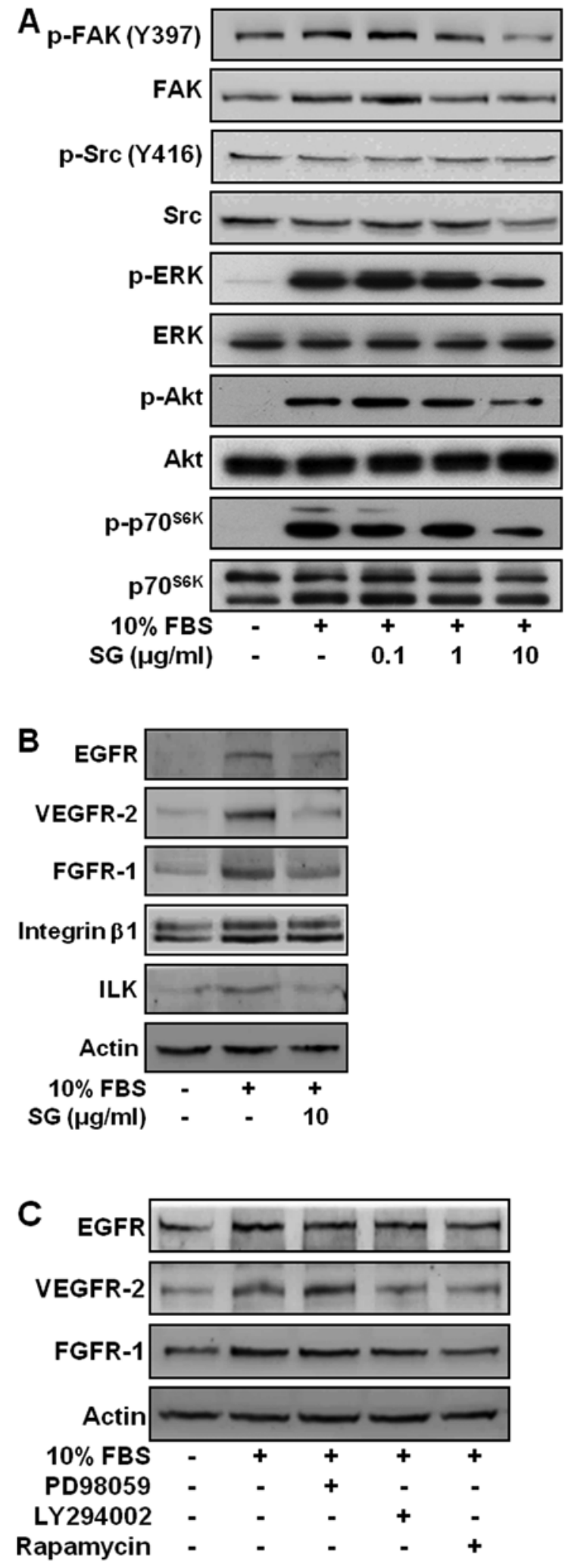

Figure 4. Changes of signaling pathways and RTK expression in SG-treated cells. (A) Quiescent cells were pretreated with SG at different concentrations $(0.1-10 \mu \mathrm{g} / \mathrm{ml})$ for $30 \mathrm{~min}$, followed by $10 \%$ serum stimulation for $15 \mathrm{~min}$ Cell lysates were western blotted with anti-phospho-FAK, anti-FAK, antiphospho-Src, anti-Src, anti-phospho-ERK, anti-ERK, anti-phospho-Akt, anti-Akt, anti-phsopho-p $70^{\mathrm{S} 6 \mathrm{~K}}$, or anti-p70 ${ }^{\mathrm{S} 6 \mathrm{~K}}$ antibodies. (B) Cells were pretreated with SG for $30 \mathrm{~min}$, followed by serum stimulation for $24 \mathrm{~h}$. Cell lysates were western blotted for EGFR, VEGFR-2, FGFR-1, integrin $\beta 1$ and ILK. (C) Cells were pretreated with PD98059 $(25 \mu \mathrm{M})$, LY294002 $(10 \mu \mathrm{M})$, or rapamycin $(50 \mathrm{nM})$ for $30 \mathrm{~min}$, and then stimulated with $10 \%$ serum for $24 \mathrm{~h}$. Cell lysates were western blotted for EGFR, VEGFR-2 and FGFR-1. Results shown are representative of three independent experiments.

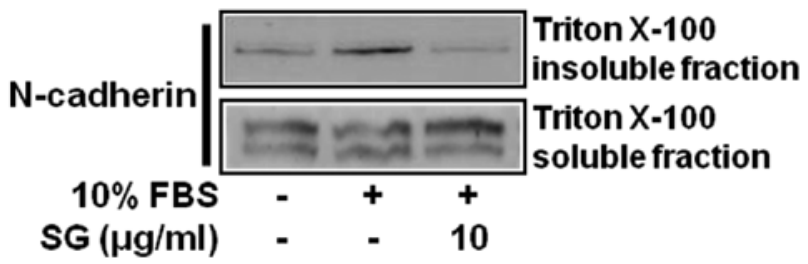

Figure 5. Regulatory effect of SG on N-cadherin distribution in cells Quiescent cells were pretreated with SG $(10 \mu \mathrm{g} / \mathrm{ml})$ for $30 \mathrm{~min}$, followed by $10 \%$ serum stimulation for $24 \mathrm{~h}$. Translocation of $\mathrm{N}$-cadherin was assessed by Triton X-100 solubility. The Triton X-100 insoluble or soluble fraction was western blotted with anti-N-cadherin antibodies. Results are representative of three independent experiments.

invasion by SG ethanol extracts might be mediated through inactivation of mitogen-stimulated signaling pathways and subsequent downregulation of RTKs and N-cadherin.

\section{Discussion}

Siegesbeckia glabrescens (SG) has mainly been used in traditional medicine for the treatment of allergic and inflammatory diseases. This application is well supported by recent studies that SG possesses pharmacologically active components such as flavones and sesquiterpene lactone to reduce inflammation $(16,17)$. In addition to anti-inflammatory activity, it has been reported to have anti-proliferative effect on breast cancer cell lines by inducing apoptosis (18). However, detailed molecular mechanisms of SG responsible for regulation of cancer growth and progression have been clearly reported to date. In the present study, we demonstrate for the first time that the ethanol extract of SG inhibits proliferation, adhesion, migration and invasion of ovarian cancer SKOV-3 cells. These antitumor activities of SG were found to be mediated through inactivation of RTK signaling pathways and downregulation of RTK and N-cadherin, as evidenced by using pharmacological inhibitors such as PD98059, LY294002 and rapamycin.

Overexpressed RTKs and dysregulation of RTK signaling pathways contribute to ovarian cancer growth and progression (4-8). These events are very complex and closely associated with EMT, a process which is controlled by a variety of signals from tumor microenvironment as well as up- and downregulation of EMT-related cellular markers (9-11).

Our results clearly show that SG treatment inhibits mitogenstimulated signaling pathways and expression of EGFR, VEGFR-2, FGFR-1, and ILK as well as N-cadherin, which plays the pivotal roles in the formation and stability of blood vessels associated with cancer growth and progression (9), similar to previous reports demonstrating that suppression of human EGFR-2 expression inhibits cell proliferation, migration and invasion through upregulation of epithelial marker E-cadherin and downregulation of mesenchymal markers $\mathrm{N}$-cadherin and vimentin in SKOV-3 cells (33). These findings suggest that cross-talk between RTKs and integrins, and interactions of cellular and ECM molecules coordinately function to regulate cancer progression within tumor microenvironment. Therefore, further understanding of the molecular mechanisms and identification of targets in ovarian cancer progression are warranted to improve therapeutic efficacy and reduce the incidence of drug resistance to cancer therapy. 
In conclusion, our findings provide important insights into the roles and pharmacological efficacy of SG in regulation of ovarian cancer growth and progression, and support the development as a potent antitumor agent for the treatment of ovarian cancer.

\section{Acknowledgements}

This study was supported by the research fund of Dankook University in 2012.

\section{References}

1. Jemal A, Bray F, Center MM, Ferlay J, Ward E and Forman D: Global cancer statistics. CA Cancer J Clin 61: 69-90, 2011.

2. Lemmon MA and Schlessinger J: Cell signaling by receptor tyrosine kinases. Cell 141: 1117-1134, 2010.

3. Hynes NE and Lane HA: ERBB receptors and cancer: the complexity of targeted inhibitors. Nat Rev Cancer 5: 341-354, 2005.

4. Alper Ö, Bergmann-Leitner ES, Bennett TA, Hacker NF, Stromberg K and Stetler-Stevenson WG: Epidermal growth factor receptor signaling and the invasive phenotype of ovarian carcinoma cells. J Natl Cancer Inst 93: 1375-1384, 2001.

5. van der Bilt ARM, de Vries EGE, de Jong S, Timmer-Bosscha $H$ van der Zee AGJ and Reyners AKL: Turning promise into progress for antiangiogenic agents in epithelial ovarian cancer. Crit Rev Oncol Hematol 84: 224-242, 2012.

6. Masoumi Moghaddam S, Amini A,Morris D and Pourgholami M: Significance of vascular endothelial growth factor in growth and peritoneal dissemination of ovarian cancer. Cancer Metastasis Rev 31: 143-162, 2012.

7. Cole C, Lau S, Backen A, et al: Inhibition of FGFR2 and FGFR1 increases cisplatin sensitivity in ovarian cancer. Cancer Biol Ther 10: 495-504, 2010.

8. Gui T and Shen K: The epidermal growth factor receptor as a therapeutic target in epithelial ovarian cancer. Cancer Epidemiol 36: 490-496, 2012.

9. Tiwari N, Gheldof A, Tatari M and Christofori G: EMT as the ultimate survival mechanism of cancer cells. Semin Cancer Biol 22: 194-207, 2012

10. Kalluri R and Weinberg RA: The basics of epithelial-mesenchymal transition. J Clin Invest 119: 1420-1428, 2009.

11. Thiery JP and Sleeman JP: Complex networks orchestrate epithelial-mesenchymal transitions. Nat Rev Mol Cell Biol 7: 131-142, 2006.

12. Lee JM, Dedhar S, Kalluri R and Thompson EW: The epithelialmesenchymal transition: new insights in signaling, development, and disease. J Cell Biol 172: 973-981, 2006.

13. Bourboulia D and Stetler-Stevenson WG: Matrix metalloproteinases (MMPs) and tissue inhibitors of metalloproteinases (TIMPs): Positive and negative regulators in tumor cell adhesion. Semin Cancer Biol 20: 161-168, 2010.

14. Kang BK, Lee EH and Kim HM: Inhibitory effects of Korean folk medicine 'Hi-Chum' on histamine release from mast cells in vivo and in vitro. J Ethnopharmacol 57: 73-79, 1997.

15. Kim H-M, Lee J-H, Won J-H, et al: Inhibitory effect on immunoglobulin E production in vivo and in vitro by Siegesbeckia glabrescens. Phytother Res 15: 572-576, 2001.
16. Kim JY, Lim HJ and Ryu J-H: In vitro anti-inflammatory activity of 3-O-methyl-flavones isolated from Siegesbeckia glabrescens. Bioorg Med Chem Lett 18: 1511-1514, 2008.

17. Li H, Kim JY, Hyeon J, Lee HJ and Ryu J-H: In vitro antiinflammatory activity of a new Sesquiterpene lactone isolated from Siegesbeckia glabrescens. Phytother Res 25: 1323-1327, 2011.

18. Jun SY, Choi YH and Shin HM: Siegesbeckia glabrescens induces apoptosis with different pathways in human MCF-7 and MDA-MB-231 breast carcinoma cells. Oncol Rep 15: 1461-1467, 2006.

19. Cho Y-R, Kim SH, Ko HY, Kim M-D, Choi SW and Seo D-W: Sepiapterin inhibits cell proliferation and migration of ovarian cancer cells via down-regulation of $\mathrm{p} 70^{\mathrm{S} 6 \mathrm{~K}}$-dependent VEGFR-2 expression. Oncol Rep 26: 861-867, 2011.

20. Seo D-W, Saxinger WC, Guedez L, Cantelmo AR, Albini A and Stetler-Stevenson WG: An integrin-binding N-terminal peptide region of TIMP-2 retains potent angio-inhibitory and antitumorigenic activity in vivo. Peptides 32: 1840-1848, 2011.

21. Kim SH, Cho Y-R, Kim H-J, et al: Antagonism of VEGF-Ainduced increase in vascular permeability by an integrin $\alpha 3 \beta 1-S h p-1-c A M P / P K A$ pathway. Blood 120: 4892-4902, 2012.

22. Yoon HJ, Cho Y-R, Joo J-H and Seo D-W: Knockdown of integrin $\alpha 3 \beta 1$ expression induces proliferation and migration of non-small cell lung cancer cells. Oncol Rep 29: 662-668, 2013.

23. Kim SH, Cho Y-R, Kim M-D, Kim HJ, Choi SW and Seo D-W: Inhibitory effects of sepiapterin on vascular endothelial growth factor-A-induced proliferation and adhesion in human umbilical vein endothelial cells. Arch Pharm Res 34: 1571-1577, 2011.

24. Cho Y-R, Choi S and Seo D-W: Sepiapterin regulates cell proliferation and migration: its association with integrin $\alpha 3 \beta 1$ and p53 in human lung cancer cells. Genes Genom 33: 577-582, 2011.

25. Bourboulia D, Jensen-Taubman S, Rittler MR, et al: Endogenous angiogenesis inhibitor blocks tumor growth via direct and indirect effects on tumor microenvironment. Am J Pathol 179: 2589-2600, 2011.

26. Hong SY, Cho JY and Seo D-W: Ginsenoside Rp1 inhibits proliferation and migration of human lung cancer cells. Biomol Ther 19: 411-418, 2011.

27. Malumbres $\mathrm{M}$ and Barbacid M: Cell cycle, CDKs and cancer: a changing paradigm. Nat Rev Cancer 9: 153-166, 2009.

28. Mitra SK, Hanson DA and Schlaepfer DD: Focal adhesion kinase: in command and control of cell motility. Nat Rev Mol Cell Biol 6: 56-68, 2005.

29. Desgrosellier JS and Cheresh DA: Integrins in cancer: biological implications and therapeutic opportunities. Nat Rev Cancer 10: 9-22, 2010 .

30. Slack-Davis JK, Atkins KA, Harrer C, Hershey ED and Conaway M: Vascular cell adhesion molecule-1 is a regulator of ovarian cancer peritoneal metastasis. Cancer Res 69: 1469-1476, 2009.

31. Eliceiri BP: Integrin and growth factor receptor crosstalk. Circ Res 89: 1104-1110, 2001.

32. Hannigan GE, McDonald PC, Walsh MP and Dedhar S: Integrinlinked kinase: Not so 'pseudo' after all. Oncogene 30: 4375-4385, 2011.

33. Lu Y-M, Rong M-L, Shang C, et al: Suppression of HER-2 via siRNA interference promotes apoptosis and decreases metastatic potential of SKOV-3 human ovarian carcinoma cells. Oncol Rep 29: 1133-1139, 2013. 